\title{
Qualitative Phytochemical Analysis and Antibacterial Activity Evaluation of Indian Terminalia spp. Against the Pharyngitis causing pathogen Streptococcus pyogenes
}

\author{
Mitchell Henry Wright, ${ }^{1}$ Megan Sarah Jean Arnold, ${ }^{2}$ Cameron Jay Lee, ${ }^{1}$ Reece Courtney, ${ }^{1,3}$ Anthony Carlson Greene, ${ }^{1}$ lan Edwin Cock ${ }^{1,3^{*}}$ \\ 'School of Natural Sciences, Nathan Campus, Griffith University, 170 Kessels Rd, Nathan, Queensland 4111, AUSTRALIA. \\ 2Eskitis Institute for Drug Discovery, GriffithUniversity, Queensland, Australia, 46 Don Young Rd, Nathan, Queensland 4111, AUSTRALIA. \\ EEnvironmental Futures Research Institute, Nathan Campus, Griffith University, 170 Kessels Rd, Nathan, Queensland 4111, AUSTRALIA.
}

\begin{abstract}
Introduction: Streptococcus pyogenes is a gram-positive, pathogenic bacterium which causes a variety of diseases including streptococcal pharyngitis, impetigo and rheumatic heart disease, depending on which tissue it infects. Many Terminalia spp. have documented therapeutic properties as general antiseptics, inhibiting the growth of a wide variety of bacterial species. Methods: Solvent extracts were prepared using Indian Terminalia spp. with documented ethnobotanical usage to treat bacterial infections, or published antibacterial activity. The extracts were investigated by disc diffusion assay for the ability to inhibit the growth of a clinical strain of S. pyogenes. Their MIC values were determined to quantify and compare their efficacies. Toxicity was determined using the Artemia franciscana nauplii bioassay. Results: T. arjuna, T. catappa and T. chebula methanolic and ethyl acetate extracts displayed potent antibacterial activity in the disc diffusion assay against $S$. pyogenes. The T. catappa and T. chebula ethyl acetate extracts were particularly potent, with MIC values of 225 and $205 \mu \mathrm{g} / \mathrm{mL}$ respectively. All methanolic extracts were also potent growth inhibitors with MIC values of $268 \mu \mathrm{g} / \mathrm{mL}$ ( $T$. arjuna methanolic extract), $425 \mu \mathrm{g} / \mathrm{mL}$ (T. catappa methanolic extract) and $300 \mu \mathrm{g} / \mathrm{mL}$ (T. chebula methanolic extract). The T. catappa hexane extract was also a potent S. pyogenes growth inhibitor (MIC $768 \mu \mathrm{g} / \mathrm{mL}$ ). All other extracts were either ineffective or were of only low efficacy. Furthermore, all of the Indian Terminalia
\end{abstract}

spp. extracts were nontoxic in the Artemia fransiscana bioassay, with $L C_{50}$ values $>1000 \mu \mathrm{g} / \mathrm{mL}$. Conclusion: The potent growth inhibitory bioactivity of the methanolic and ethyl acetate T. arjuna, T. catappa and $T$. chebula extracts against $S$. pyogenes demonstrates their potential for the treatment and prevention of pharyngitis, impetigo and rheumatic heart disease. All extracts were nontoxic indicating their safety for therapeutic use.

Key words: Terminalia arjuna, Terminalia catappa, Terminalia chebula pharyngitis, Impetigo, Rheumatic heart disease, Antibacterial activity, Ayurveda.

\section{Correspondence:}

Ian Edwin Cock,

School of Natural Sciences, Nathan Campus,

Griffith University, 170 Kessels Rd, Nathan,

Queensland 4111, AUSTRALIA

Tel no.: +61 737357637 ; Fax no: +61 737355282

E-mail: i.cock@griffith.edu.au (I. E. Cock)

DOI : $10.5530 /$ pc.2016.2.6

\section{INTRODUCTION}

The genus Streptococcus comprises over 50 different species of grampositive, non-sporulating cocci-shaped bacteria. Found in a diverse range of environments including soils, or as part of the natural human microflora, Streptococcus spp. are primarily facultatively anaerobic, however some are obligate anaerobes. ${ }^{1}$ Many species within the genus are pathogenic and responsible for an extensive variety of diseases. Pathogens within the genus can infect ruminants, humans or cause disease inboth people and animals. ${ }^{2}$ Diseases in humans can vary and range from non-life threatening epithelial/throat infections, such as pharyngitis or skin infections including impetigo and scarlet fever, to potentially fatal internal infections such as pneumonia, necrotizing fasciitis, toxic shock syndrome or meningitis, ${ }^{3,4}$ Some Streptococcus species can also trigger autoimmune rheumatic heart disease. ${ }^{5}$

Streptococcus spp. are grouped according to their haemolytic peoperties and Lancefield serotyping. Group A streptococcal pharyngitis is an acute infection of the nasopharynx and/or oropharynx and is initiated through infection by Streptococcus pyogenes. ${ }^{6}$ S. pyogenes infections are the most common bacterial cause of pharyngitis and are responsible for up to 33\% of all diagnosed cases of sore throat in children, and up to $10 \%$ in adults. ${ }^{7}$ Though mostly non-life threatening, Group A streptococcal infections are a significant economic burden. Indeed, recent estimates place the societal cost (both medical and nonmedical) in the United States alone ranging from $\$ 224$ to $\$ 539$ million dollars annually. ${ }^{8}$ While the bacterium responds well to antibiotic treatment, ${ }^{7}$ the increasing risk of drug resistance highlights the need to develop alternatives to fight these and other diseases. The probing of natural plant resources for previously undiscovered antibacterial products offers an alternative to the traditional drug design and synthesis.

One of the most useful genera of therapeutic plants is Terminalia. This genus encompasses approximately 200-250 species of flowering trees and has extensive uses in multiple traditional medicinal systems. ${ }^{9}$ The antibacterial activity of Terminalia spp. has been particularly well reported. Extracts prepared from the fruit of the Australian species Terminalia ferdinandiana (Kakadu plum) have potent growth inhibitory activity against an extensive panel of pathogens including bacteria associated diarrhoea and dysentery ${ }^{10}$ as well as the bacterial triggers of rheumatoid arthritis (Proteus mirabilis) ${ }^{11}$ and multiple sclerosis (Acinitobacter baylyi and Pseudomonas aeruginosa). ${ }^{12}$ Leaf extracts from the same species have also been shown to inhibit growth of the same bacteria, as well as a microbial trigger of ankylosing spondylitis (Klebsiella pneumoniae). ${ }^{13}$ Similarly, African Terminalia spp. have been shown to be potent bacterial growth inhibitors. Terminalia stenostachya and Terminalia spinosa have strong antibacterial activity against a broad spectrum of medicinally important bacteria including several Mycobacterium spp., Streptococcus faecalis, Staphylococcus aureus, Vibrio cholera, Bacillus anthracis, K. pneumoniae, Salmonella typhi, P. aeruginosa and Escherichia coli. ${ }^{14}$ 
Recent studies have demonstrated the growth inhibitory activity of Terminalia sericea and Terminalia pruinoides against pathogenic ${ }^{15-17}$ and food spoilage bacteria. ${ }^{18}$

The traditional therapeutic uses of the Indian Terminalia have been the best documented of all Terminalia spp. due to their usage in multiple medicinal systems, including Ayurverda, Siddha and Unani. Many species are used to treat multiple diseases caused by microbial infections (Table 1). Numerous recent investigations have reported on their antibacterial properties. Leaf and branch extracts of Terminalia arjuna, have antibacterial activity against a wide panel of microbes. ${ }^{19,20}$ Terminalia chebula has traditional uses in Ayurveda for the treatment of numerous diseases and conditions ${ }^{21}$ and has potent antibacterial activity. ${ }^{19}$ Indeed, a recent study has even highlighted their potential in the prevention and treatment of anthrax. ${ }^{22}$ Terminalia alata, Terminalia bellirica and Terminalia catappa also have broad spectrum antibacterial activity. ${ }^{20}$ However, despite the wealth of antibacterial studies for Terminalia spp., there is a lack of studies screening Terminalia spp. for the ability to inhibit $S$. pyogenes growth and thus their therapeutic value for the prevention and treatment of streptococcal pharyngitis, impetigo, rheumatic heart disease etc. Indeed, a literature search only found a single study which reported $S$. pyogenes growth inhibitory activity for the Indian Terminalia spp. T. chebula. ${ }^{23}$ However, whilst anti-Streptococcal activity was reported, the value of that study is limited as the extracts were screened only with a single, relatively high extract concentration. Our study was undertaken to examine the ability of selected Asian Terminalia spp. with extensive usage in Ayurvedic medicine for the ability to inhibit $S$. pyogenes growth.

\section{MATERIALS AND METHODS}

\section{Plant source and extraction}

Terminalia arjuna, Terminalia catappa and Terminalia chebula plant materials used throughout this study were kindly provided by Dr. Paran Rayan, Griffith University. Voucher samples of all plant specimens have been stored at the School of Natural Sciences, Griffith University, Brisbane Australia. The plant materials were comprehensively desiccated in a Sunbeam food dehydrator and the dried materials kept at $-30^{\circ} \mathrm{C}$ until use. Prior to usage, the materials were thawed and ground into a coarse powder.Individual $1 \mathrm{~g}$ amounts of the material were weighed into separate tubes and $50 \mathrm{~mL}$ of deionised water, methanol, chloroform, hexane and ethyl acetate were added. All solvents were AR grade and were obtained from Ajax, Australia. The ground plant materials were individually extracted in each solvent for $24 \mathrm{~h}$ at $4^{\circ} \mathrm{C}$ using gentle shaking. The extracts were then filtered through filter paper (Whatman No. 54) under vacuum, followed by drying by rotary evaporation in an Eppendorf concentrator 5301. The resultant extracts were weighed and redissolved in $10 \mathrm{~mL}$ deionised water (containing $1 \% \mathrm{DMSO}$ ).

\section{Qualitative phytochemical studies}

Phytochemical analysis of the extracts for the presence of triterpenoids, tannins, saponins, phytosteroids, phenolic compounds, flavonoids, cardiac glycosides, anthraquinones and alkaloids was performed as previously described. ${ }^{24-26}$

\section{Antibacterial screening Clinical Streptococcus pyogenes strain}

All media was supplied by Oxoid Ltd., Australia. The clinical isolate strain of Streptococcus pyogenes used in this study was donated by Michelle Mendell of the School of Natural Sciences Griffith University, Australia. All growth studies were performed using nutrient agar (Oxoid Ltd., Australia) under aerobic conditions. Incubation was at $37^{\circ} \mathrm{C}$ and the stock culture was subcultured and maintained in nutrient broth at $4^{\circ} \mathrm{C}$.

\section{Evaluation of antimicrobial activity}

The antimicrobial activity of the T. arjuna, T. chebula and T. catappa plant extracts was assessed using a modified disc diffusion assay as previously described. ${ }^{16,27,28}$ Briefly, $100 \mu \mathrm{L}$ of $S$. pyogenes was grown in $10 \mathrm{~mL}$ of fresh nutrient broth until a cell count of $\sim 10^{8}$ cells $/ \mathrm{mL}$ was attained. A $100 \mu \mathrm{L}$ volume of bacterial suspension was spread onto nutrient agar plates. The antibacterial activity of the extracts was tested using $5 \mathrm{~mm}$ sterilised filter paper discs. Discs were infused with $10 \mu \mathrm{L}$ of the each individual extract, allowed to dry and placed onto inoculated plates. The plates were allowed to stand at $4^{\circ} \mathrm{C}$ for $2 \mathrm{~h}$ before incubation at $30^{\circ} \mathrm{C}$ for $24 \mathrm{~h}$. The diameters of the inhibition zones were measured in millimetres. All measurements were rounded to the closest whole millimetre. Each assay was performed in at least triplicate. Mean values $( \pm$ SEM) are reported in this study. Standard discs of ampicillin $(10 \mu \mathrm{g})$ were obtained from Oxoid Ltd. and served as positive controls for antibacterial activity. Filter discs infused with $10 \mu \mathrm{L}$ of sterilised water were used as a negative control.

\section{Minimum inhibitory concentration (MIC) determination}

The minimum inhibitory concentration (MIC) of each extract was assessed as previously described. ${ }^{29,30}$ Briefly, the plant extracts were diluted in deionised water and tested across a range of concentrations. Discs were infused with $10 \mu \mathrm{L}$ of the test dilutions, allowed to dry and placed onto inoculated plates. The assay was performed as outlined above and graphs of the zone of inhibition versus concentration were plotted for each extract. Linear regression was used to determine the MIC values of each extract.

\section{Toxicity screening \\ Reference toxin for toxicity screening}

Potassium dichromate $\left(\mathrm{K}_{2} \mathrm{Cr}_{2} \mathrm{O}_{7}\right)$ (AR grade, Chem-Supply, Australia) was prepared as a $4 \mathrm{mg} / \mathrm{mL}$ solution in distilled water and was serially diluted in artificial seawater for use in the Artemia franciscana nauplii bioassay.

\section{Artemia franciscana nauplii toxicity screening}

Toxicity was tested using an adapted Artemia franciscana nauplii lethality assay as previously described. ${ }^{31-33}$ Briefly, $400 \mu \mathrm{L}$ of seawater containing $\sim 52$ (mean=52.3, $\mathrm{n}=120, \mathrm{SEM}=12.6)$ A. franciscana nauplii were added to wells of a 48 well plate and immediately used for bioassay. A volume of $400 \mu \mathrm{L}$ of diluted plant extracts or the reference toxin were transferred to the wells and incubated at $25 \pm 1^{\circ} \mathrm{C}$ under artificial light (1000 Lux). A negative control ( $400 \mu \mathrm{L}$ seawater) was run in triplicate for each plate. All treatments were performed in at least triplicate. The wells were checked at regular intervals and the number of dead counted. The nauplii were deemed dead if no movement of the appendages was detected within $10 \mathrm{sec}$. Following $24 \mathrm{~h}$ exposure, all nauplii were sacrificed and counted to determine the total \% mortality per well. The $\mathrm{LC}_{50}$ with $95 \%$ confidence limits for each treatment was assessed using probit analysis.

\section{Statistical analysis}

Data are expressed as the mean \pm SEM of at least three independent experiments.

\section{RESULTS}

\section{Liquid extraction yields and qualitative phytochemical screening}

Extraction of $1 \mathrm{~g}$ of the various dried Terminalia spp. materials with the solvents yielded dried plant extracts ranging from $22 \mathrm{mg}$ (T. arjuna 


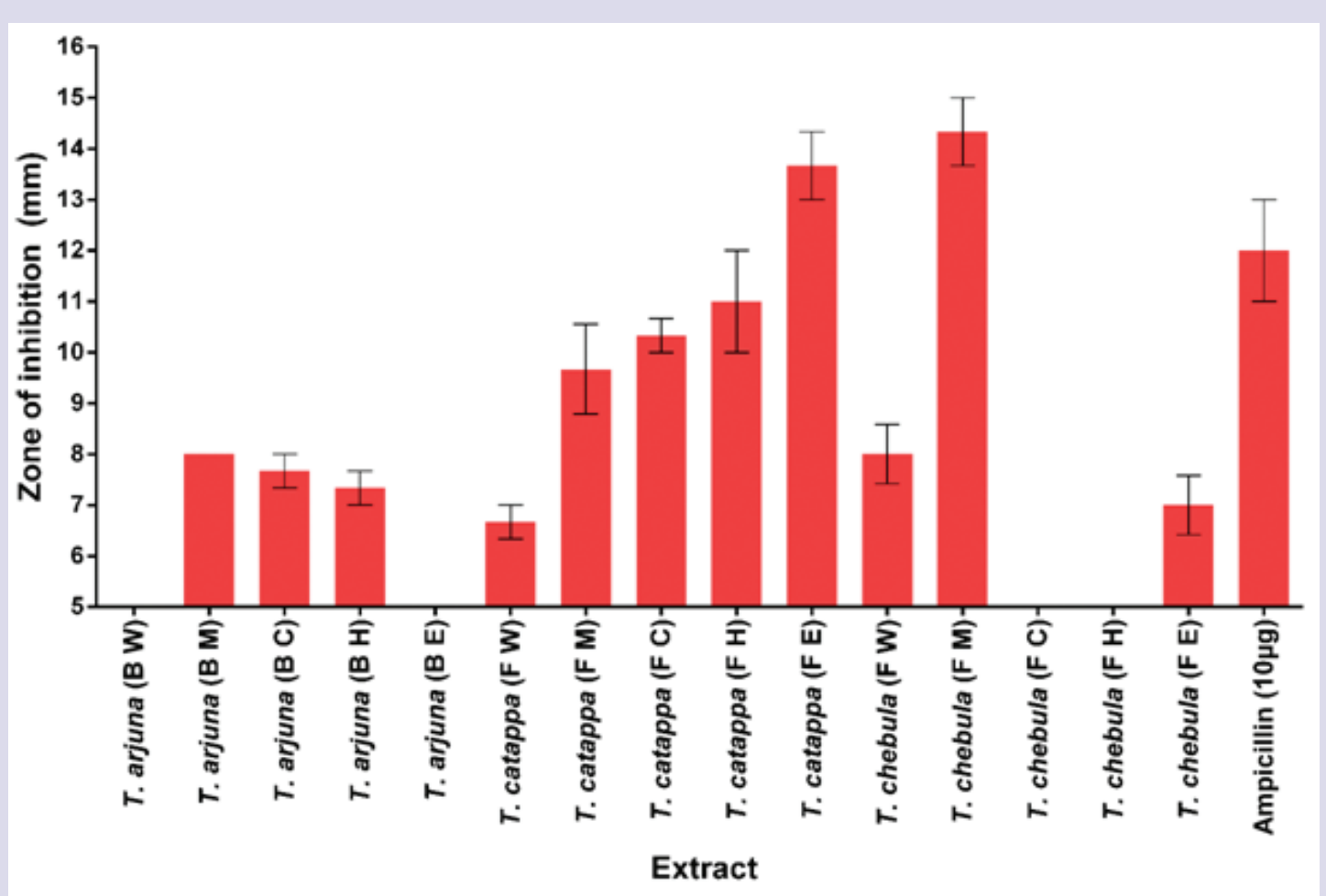

Figure 1: Growth inhibitory activity of the Terminalia spp. extracts against the S. pyogenes clinical isolate measured as zones of inhibition (mm). B=branch; $\mathrm{F}=$ fruit; $\mathrm{W}=$ aqueous extract; $\mathrm{M}=$ methanolic extract; $\mathrm{C}=$ chloroform extract; $\mathrm{H}=$ hexane extract; $\mathrm{E}=$ ethyl acetate extract. Results are expressed as mean zones of inhibition \pm SEM

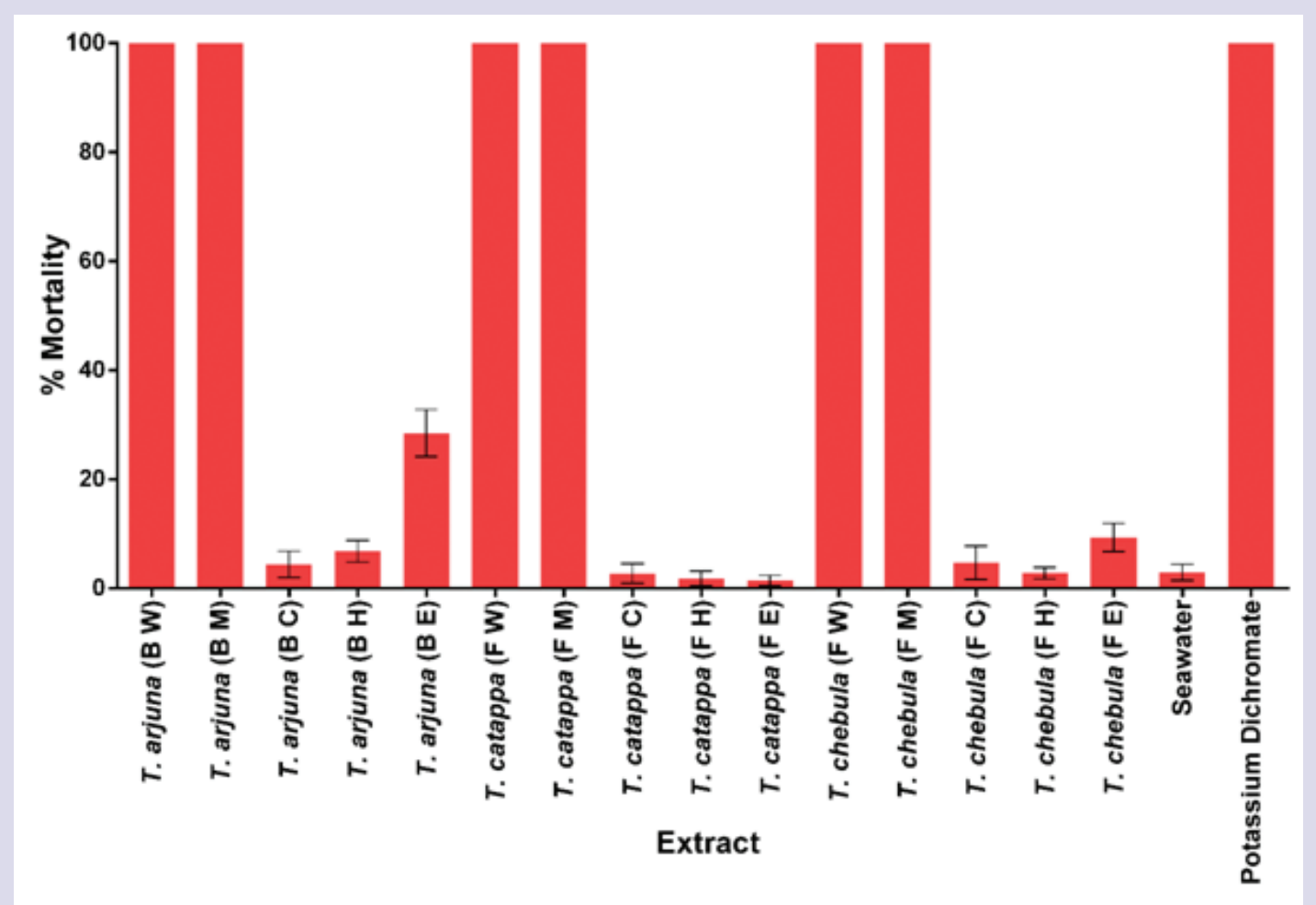

Figure 2: The lethality of the Terminalia spp.extracts $(2000 \mu \mathrm{g} / \mathrm{mL})$ and the potassium dichromate $(1000 \mu \mathrm{g} / \mathrm{mL})$ and seawater controls towards Artemia franciscana nauplii after $24 \mathrm{~h}$ exposure. $\mathrm{F}=$ fruit; $\mathrm{B}=$ branch; $\mathrm{W}=$ aqueous extract; $\mathrm{M}=$ =methanolic extract; $\mathrm{C}=$ chloroform extract; $\mathrm{H}=$ hexane extract; $\mathrm{E}=$ =ethyl acetate extract. Results are expressed as mean $\%$ mortality \pm SEM. 
Table 1: The medicinal usage, common names and known constituents of the Indian Terminalia species tested in this study

\begin{tabular}{|c|c|c|c|c|c|}
\hline Plant Species & $\begin{array}{l}\text { Part Used in } \\
\text { This Study }\end{array}$ & Common Name/s & Traditional Medicinal Uses & Known Constituents & References \\
\hline $\begin{array}{l}\text { Terminalia } \\
\text { arjuna }\end{array}$ & branch & $\begin{array}{l}\text { Arjuna, Koha, } \\
\text { White Marudah }\end{array}$ & $\begin{array}{l}\text { Treatment of cardiovascular disorders as well as } \\
\text { anti-inflammatory properties. Known to aid in } \\
\text { the elimination of cholesterol. Also an analgesic } \\
\text { and an antioxidant. }\end{array}$ & $\begin{array}{l}\text { Triterpenoids, flavonoids, } \\
\text { tannins, gallic and } \\
\text { ellagic acid, sitosterol, } \\
\text { proanthocyanidins }\end{array}$ & 9 \\
\hline $\begin{array}{l}\text { Terminalia } \\
\text { catappa }\end{array}$ & fruit & $\begin{array}{l}\text { Indian almond, } \\
\text { tropical almond, } \\
\text { umbrella tree }\end{array}$ & $\begin{array}{l}\text { Therapeutic effects for liver related diseases, } \\
\text { anticancer activity as well as effective in } \\
\text { the blocking of HIV reverse transcriptase. } \\
\text { Additionally known to have antidiabetic benefits. }\end{array}$ & $\begin{array}{l}\text { Flavonoids (including } \\
\text { kaempferol, quercetin), } \\
\text { tannins, saponins and } \\
\text { phytosterols }\end{array}$ & 9 \\
\hline $\begin{array}{l}\text { Terminalia } \\
\text { chebula }\end{array}$ & fruit & $\begin{array}{l}\text { Chebulic } \\
\text { Myroblan, } \\
\text { Black Myroblan, } \\
\text { Haritaki, Inknut }\end{array}$ & $\begin{array}{l}\text { Used externally to treat fungal infections and } \\
\text { cutaneous wounds and in the prevention of } \\
\text { inflammation of the mucosal membrane of the } \\
\text { mouth. Used internally as a laxative and is known } \\
\text { for its purgativeeffects. Known to have uses in the } \\
\text { treatment of asthma and coughs. }\end{array}$ & $\begin{array}{l}\text { Terflavin B and chebulinic } \\
\text { acid }\end{array}$ & 9 \\
\hline
\end{tabular}

Table 2: The mass of dried extracted material, the concentration after resuspension in deionised water and qualitative phytochemical screenings of the plant extracts

\begin{tabular}{|c|c|c|c|c|c|c|c|c|c|c|c|c|c|c|c|c|c|}
\hline 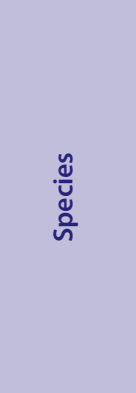 & 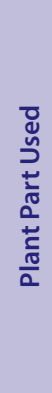 & 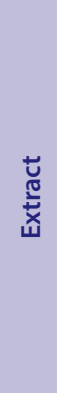 & 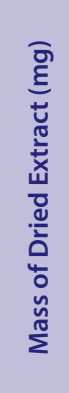 & 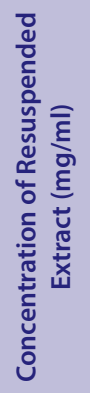 & 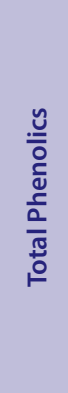 & 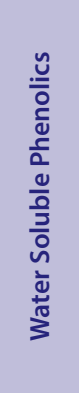 & 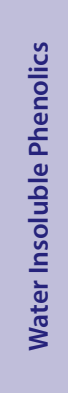 & 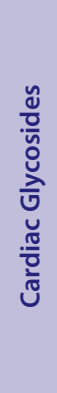 & 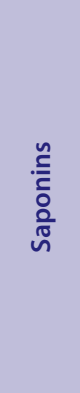 & 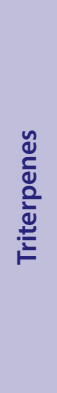 & $\begin{array}{l}\frac{n}{0} \\
\frac{0}{0} \\
\frac{\tilde{N}}{2} \\
\frac{0}{0}\end{array}$ & 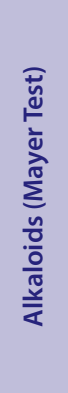 & 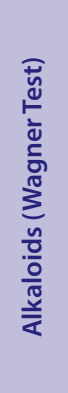 & $\begin{array}{l}\frac{n}{0} \\
\frac{0}{0} \\
\frac{0}{\pi} \\
\frac{\pi}{4}\end{array}$ & 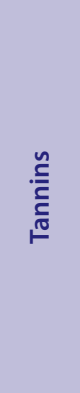 & 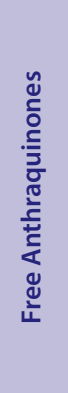 & 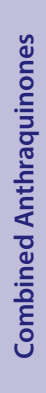 \\
\hline T. arjuna & B & $\mathrm{W}$ & 144 & 14.4 & ++ & +++ & +++ & - & ++ & - & - & - & - & +++ & +++ & + & - \\
\hline T. arjuna & B & M & 40 & 4 & ++ & +++ & +++ & - & +++ & - & - & - & - & +++ & +++ & + & - \\
\hline T. arjuna & B & $\mathrm{C}$ & 92 & 9.2 & + & + & - & - & - & - & - & - & - & - & + & - & - \\
\hline T. arjuna & B & $\mathrm{H}$ & 136 & 13.6 & - & - & - & - & - & - & - & - & - & - & - & - & - \\
\hline T. arjuna & B & $\mathrm{E}$ & 22 & 2.2 & + & - & - & - & - & - & - & - & - & + & + & - & - \\
\hline T. catappa & $\mathrm{F}$ & $\mathrm{W}$ & 144 & 14.4 & +++ & +++ & ++ & + & ++ & - & - & ++ & ++ & ++ & +++ & - & - \\
\hline T. catappa & $\mathrm{F}$ & M & 231 & 23.1 & +++ & +++ & ++ & + & - & - & - & + & ++ & ++ & +++ & - & - \\
\hline T. catappa & $\mathrm{F}$ & $\mathrm{C}$ & 434 & 43.4 & + & + & - & + & - & - & - & - & - & + & + & - & - \\
\hline T. catappa & $\mathrm{F}$ & $\mathrm{H}$ & 447 & 44.7 & + & + & - & - & - & - & - & - & - & - & + & - & - \\
\hline T. catappa & $\mathrm{F}$ & E & 353 & 35.3 & + & + & - & - & - & - & - & - & - & + & + & - & - \\
\hline T. chebula & $\mathrm{F}$ & $\mathrm{W}$ & 438 & 43.8 & +++ & +++ & +++ & - & +++ & - & - & - & - & +++ & +++ & ++ & - \\
\hline T. chebula & $\mathrm{F}$ & M & 634 & 63.4 & +++ & +++ & +++ & - & +++ & - & - & - & - & +++ & +++ & ++ & - \\
\hline T. chebula & $\mathrm{F}$ & $\mathrm{C}$ & 93 & 9.3 & + & - & - & - & - & - & - & - & - & - & + & - & - \\
\hline T. chebula & $\mathrm{F}$ & $\mathrm{H}$ & 104 & 10.4 & - & - & - & - & - & - & - & - & - & - & - & ++ & - \\
\hline T. chebula & $\mathrm{F}$ & $\mathrm{E}$ & 62 & 6.2 & +++ & ++ & + & - & - & - & - & - & - & +++ & +++ & - & - \\
\hline
\end{tabular}

+++ indicates a large response; ++ indicates a moderate response; + indicates a minor response; - indicates no response in the assay. $\mathrm{F}=$ fruit; $\mathrm{B}=$ branch; $\mathrm{W}=$ aqueous extract; $\mathrm{M}=$ methanolic extract; $\mathrm{C}=$ chloroform extract; $\mathrm{H}=$ hexane extract; $\mathrm{E}=$ ethyl acetate extract. 
ethyl acetate leaf extract) to $634 \mathrm{mg}$ (T. chebula methanolic fruit extract) (Table 2). Typically, T. chebula fruit extracts gave higher yields compared to T. arjuna and T. catappa extracted materials. However, this trend was not observed in the lower polarity fruit extracts (hexane and chloroform) obtained from T. catappa, which had significantly higher yields compared to those of T. arjuna and T. chebula. Indeed, the T. catappa hexane and chloroform extracts had approximately double the yields when compared to the corresponding methanolic or aqueous extracts.

Qualitative phytochemical studies showed that the methanolic and aqueous extracts generally had an extensive range of phytochemicals (Table 2). Both these solvents typically extracted greater levels of phenolics (especially water soluble phenolics) for all plant materials. Additionally, these extracts generally yielded high levels of tannins and flavonoids and moderate to high levels of saponins. Similarly, the ethyl acetate extracts had similar phytochemical profiles to the aqueous and methanolic counterparts. However, most classes of compounds were present in only lower relative abundances. Conversely, the chloroform and hexane extracts of most of the Terminalia spp. typically only had low to moderate levels of phenolics, flavonoids and tannins and were generally devoid of detectable levels of the other phytochemical classes.

\section{Antimicrobial activity}

To assess the inhibitory activity of the crude plant extracts against S. pyogenes, $10 \mu \mathrm{L}$ aliquots of each extract were screened using a disc diffusion assay. The bacterial growth was inhibited by 11 of the 15 extracts tested ( 73\%) (Figure 1$)$. The T. catappa ethyl acetate and T. chebula me thanolic extracts were the most potent inhibitors of $S$. pyogenes growth (as judged by zones of inhibition), with inhibition zones of $13.6 \pm 0.7 \mathrm{~mm}$ and $14.3 \pm 0.7 \mathrm{~mm}$ respectively. This compares favourably with the ampicillin control, which had an inhibitory zone of $12.0 \pm 1.0 \mathrm{~mm}$. Collectively, T. catappa extracts were the best inhibitors of growth, with all extracts testing positive and the methanolic, chloroform and hexane extracts giving $>9 \mathrm{~mm}$ inhibitory zones.

The antimicrobial efficacy was further quantified by determining the MIC values (Table 3). In general, the ethyl acetate extracts were the most potent inhibitors of $S$. pyogenes growth, with MIC values of approximately $200 \mu \mathrm{g} / \mathrm{mL}$ ( $2 \mu \mathrm{g}$ infused into the disc). The T. arjuna ethyl acetate extract defied this trend with no growth inhibitory activity evident for this extract at all. However, it is noteworthy that this extract was the least concentrated of the tested extracts and it is possible it may have exhibited activity if tested at a higher concentration. Similarly potent $P$. pyogenes growth inhibition was also noted for the methanolic extracts of all Terminalia spp. (MIC values $250-400 \mu \mathrm{g} / \mathrm{mL}$ ). With the exceptions of the T. arjuna chloroform and hexane extracts, the T. catappa hexane extract and the aqueous $T$. chebula extract (which displayed moderate growth inhibitory activity), all other extracts were ineffective at inhibiting $S$. pyogenes growth.

\section{Quantification of toxicity}

All extracts were initially screened at $2000 \mu \mathrm{g} / \mathrm{mL}$ in the assay (Figure 2). For comparison, the reference toxin potassium dichromate $(1000 \mu \mathrm{g} / \mathrm{mL})$ was also assessed in the bioassay. The potassium dichromate reference toxin was rapid in its onset, inducing nauplii death within the first $3 \mathrm{~h}$ of exposure and $100 \%$ mortality evident in the subsequent $4-5 \mathrm{~h}$ (unpublished results). The methanolic and aqueous extracts of all Terminalia spp. were toxic in the Artemia nauplii bioassay, with $\geq 50 \%$ mortality rates at $24 \mathrm{~h}$. The mortality for all other extracts was not significantly different to the mortality seen for the seawater control.

To further enumerate the effect of toxin concentration on the induction of mortality, the extracts were serially diluted in artificial seawater to test across a range of concentrations in the Artemia nauplii bioassay.
Table 3 shows the $\mathrm{LC}_{50}$ values of the extracts towards $A$. franciscana. No $\mathrm{LC}_{50}$ values are reported for the ethyl acetate, chloroform or hexane extracts of any Terminalia spp. as $\leq 50 \%$ mortality was seen across concentrations tested. All other extracts were deemed nontoxic as they yielded $\mathrm{LC}_{50}$ values substantially greater than $1000 \mu \mathrm{g} / \mathrm{mL}$ following $24 \mathrm{~h}$ exposure. Extractswith $\mathrm{LC}_{50}$ values of $\geq 1000 \mu \mathrm{g} / \mathrm{mL}$ towards Artemia nauplii are deemed to be nontoxic. ${ }^{33}$

\begin{tabular}{|c|c|c|c|c|}
\hline Species & Part & Extract & MIC $(\mu \mathrm{g} / \mathrm{mL})$ & $\mathrm{LC}_{50}(\mu \mathrm{g} / \mathrm{mL})$ \\
\hline T. arjuna & B & $\mathrm{W}$ & - & 2094 \\
\hline T. arjuna & B & M & 268 & 1683 \\
\hline T. arjuna & B & $\mathrm{C}$ & 2581 & - \\
\hline T. arjuna & B & $\mathrm{H}$ & 3300 & - \\
\hline T. arjuna & B & $\mathrm{E}$ & - & - \\
\hline T. catappa & $\mathrm{F}$ & $\mathrm{W}$ & $>10,000$ & 1873 \\
\hline T. catappa & $\mathrm{F}$ & M & 425 & 1452 \\
\hline T. catappa & F & $\mathrm{C}$ & $>10,000$ & - \\
\hline T. catappa & $\mathrm{F}$ & $\mathrm{H}$ & 768 & - \\
\hline T. catappa & F & E & 225.1 & - \\
\hline T. chebula & $\mathrm{F}$ & W & 2677 & 2246 \\
\hline T. chebula & $\mathrm{F}$ & M & 300 & 1883 \\
\hline T. chebula & F & $\mathrm{C}$ & - & - \\
\hline T. chebula & $\mathrm{F}$ & $\mathrm{H}$ & - & - \\
\hline T. chebula & F & E & 205 & - \\
\hline
\end{tabular}

Numbers indicate the mean MIC and $\mathrm{LC}_{50}$ values of triplicate determinations. - indicates no bacterial growth inhibition was evident, or that an $\mathrm{LC}_{50}$ value could not be obtained as the mortality did not reach $50 \%$ for any dose tested. $\mathrm{F}=$ fruit; $\mathrm{B}=$ branch; $\mathrm{W}=$ =aqueous extract; $\mathrm{M}=$ methanolic extract; $\mathrm{C}=$ chloroform extract; $\mathrm{H}=$ hexane extract; $\mathrm{E}=$ ethyl acetate extract.

\section{DISCUSSION}

Members of genus Terminalia have been used for a broad range of medicinal purposes by traditional healers from a wide variety of ethnic and cultural groupings. The best documented of these are the traditional Indian medicinal systems, particularly the Ayurveda. Ayurvedic practitioners employ various Terminalia spp. for a wide variety of medicinal purposes including abdominal and back pain, coughs and colds, conjunctivitis, diarrhoea and dysentery, fever, headache, heart disorders, inflammation, leprosy, pneumoniae, sexually transmitted diseases, worms, wounds, haemorrhages, ulcers, and as a general tonic. ${ }^{9}$ Many of these diseases are caused by microbial pathogens, indicating the potential of these plants as antiseptic agents and numerous recent investigations have reported on their antibacterial properties. T. arjuna leaf and branch extracts have antibacterial activity against a wide panel of microbes. ${ }^{9,19,20}$ T. chebula also has a tradition of use in Ayurveda for the treatment of numerous diseases and conditions. ${ }^{9,21}$ T. chebula has also been reported to display potent antibacterial activity against a microbial panel. ${ }^{19}$ Similarly, T. alata, T. bellirica and T. catappa have been reported to have broad spectrum antibacterial activity. ${ }^{20}$

The growth inhibitory activity of the Indian Terminalia spp. extracts against $S$. pyogenes is particularly noteworthy for the development of 
future antibiotic chemotherapeutics. Aside from the obvious antibiotic applications to directly treat localised throat (pharyngitis) and skin infections (impetigo), ${ }^{6,7}$ a number of substantially more serious illnesses are caused by acute and chronic $S$. pyogenes infections and may also benefit from treatment with these extracts. When $S$. pyogenes invades and colonises deeper tissue it can lead to erysipelas and cellulitis, conditions characterised by localised red, swollen and painful areas, and often by fever and lethargy. ${ }^{2-4}$ If not promptly treated, bacterium can spread to other areas via the bloodstream which may result in serious tissue damage and autoimmune diseases such as glomerulonephritis (inflammation of the glomeruli in the kidneys), lymphedema (inflammation of lymph nodes), septic arthritis and rheumatic fever (inflammation of cardiac tissue).$^{3-5}$ Furthermore, acute $S$. pyogenes infections of subcutaneous tissues can induce the potentially fatal disease necrotizing fasciitis. ${ }^{4}$ These conditions are not only highly debilitating, but may also be life threatening and new, more effective treatment regimens could potentially prolong and increase the quality of life as well as reducing the burden on the health system. The efficacy of the Indian Terminalia spp. extracts indicates that they may have potential in the treatment of these illnesses and further investigation is warranted.

Whilst an examination of the phytochemistry of the Terminalia spp. was beyond the scope of our study, a commonality of this genus is their relatively high levels of a number of tannin components including exifone (4-galloylpyrogallol), ellagic acid dehydrate, trimethyl ellagic acid, chebulic acid, corilagen, castalagin and chebulagic acid. ${ }^{9,11-13}$ Gallotannins have been reported to inhibit the growth of a broad spectrum of bacterial species ${ }^{34}$ through a variety of mechanisms including binding cell surface molecules including lipoteichoic acid and proline-rich cell surface proteins, ${ }^{35,36}$ and by inhibiting glucosyltransferase enzymes. ${ }^{37}$ Ellagitannins are also highly potent inhibitors of bacterial growth, with MIC values as low as $62.5 \mu \mathrm{g} / \mathrm{ml} .^{34}$ Ellagitannins have also been reported to function via several antibiotic mechanisms including interaction with cytoplasmic oxidoreductases and by disrupting bacterial cell walls. ${ }^{34,36}$

It is likely that other phytochemical classes also contribute to the growth inhibitory properties of these extracts. Our qualitative phytochemical screening studies indicate that polyphenolics, flavonoids, saponins, and terpenes were present in the Terminalia spp. extracts. Terpenoids have been previously reported to have potent broad spectrum antibacterial activity $^{38}$ and therefore may contribute to the inhibitory activity against $S$. pyogenes. Many studies have also reported potent antibacterial activities for a wide variety of flavonoids. ${ }^{39}$ Further phytochemical evaluation studies and bioactivity driven isolation of active components is required to further evaluate the mechanism of $S$. pyogenes growth inhibition.

The findings reported here also demonstrate that all of the Indian Terminalia spp. extracts tested in our study were nontoxic towards Artemia franciscana nauplii, with $\mathrm{LC}_{50}$ values substantially $>1000 \mu \mathrm{g} / \mathrm{mL}$. Extracts with $\mathrm{LC}_{50}$ values $>1000 \mu \mathrm{g} / \mathrm{mL}$ towards Artemia nauplii are defined as being nontoxic. ${ }^{33}$ Whilst our preliminary toxicity studies indicate that these extracts may be safe for use as $S$. pyogenes growth inhibitors, studies using human cell lines are required to further evaluate the safety of these extracts.

\section{ACKNOWLEDGEMENTS}

We are grateful to Dr Paran Rayan for supplying the plant specimens and to Michelle Mendell for the gift of the S. pyogenes clinical isolate strain used in this study. Financial support for this work was provided by the Environmental Futures Research Institute and the School of Natural Sciences, Griffith University, Australia.

\section{CONFLICTS OF INTEREST}

The authors report no conflicts of interest.

\section{ABBREVIATION USED}

DMSO: Dimethyl sulfoxide, $\mathbf{L C}_{50}$ : The concentration required to achieve 50\% mortality, MIC: Minimum inhibitory concentration.

\section{REFERENCES}

1. Patterson MJ. Streptococcus. In: Baron S, editor. Medical Microbiology. 4th edition. Chapter 13. Galveston (TX): University of Texas Medical Branch at Galveston 1996. Available from: http://www.ncbi.nlm.nih.gov/books/NBK7611/

2. Wertheim HFL, Nghia HDT, Taylor W. Streptococcus suis: An Emerging Human Pathogen. Clin Infect Dis. 2009;48(5):617-25.

3. O'Brien KL, Wolfson LJ, Watt JP. Burden of disease caused by Streptococcus pneumoniae in children younger than 5 years: global estimates. The Lancet. 2009;374(9693):893-902.

4. Johansson L, Thulin P, Low DE. Getting under the skin: The Immunopathogenesis of Streptococcus pyogenes deep tissue infections. Clinical Infectious Diseases. 2010;51(1):58-65.

5. Gerber MA, Baltimore RS, Eaton CB. Prevention of rheumatic fever and diagnosis and treatment of acute Streptococcal pharyngitis. A scientific statement from the American Heart Association Rheumatic Fever, Endocarditis, and Kawasaki Disease Committee of the Council on Cardiovascular Disease in the Young, the Interdisciplinary Council on Functional Genomics and Translational Biology, and the Interdisciplinary Council on Quality of Care and Outcomes Research: Endorsed by the American Academy of Pediatrics. Circulation. 2009;119(11):1541-51.

6. Bisno AL, Gerber MA, Gwaltney JM. Practice Guidelines for the Diagnosis and Management of Group A Streptococcal Pharyngitis. Clinical Infectious Diseases. 2002;35(2):113-25

7. Worrall GJ. Acute sore throat. Canadian Family Physician. 2007;53(11):1961-2.

8. Pfoh E, Wessels MR, Goldmann D. Burden and economic cost of group A streptococcal pharyngitis. Pediatrics. 2008;121(2):229-34

9. Cock IE. The medicinal properties and phytochemistry of plants of the genus Terminalia (Combretaceae). Inflammopharmacology. 2015;23(5):203-29. DOI 10.1007/s10787-015-0246-z

10. Cock IE, Mohanty S. Evaluation of the antibacterial activity and toxicity of Terminalia ferdinandiana fruit extracts. Pharmacognosy Journal. 2011;3(20):72-9. DOI: 10.5530/pj.2011.20.14

11. Sirdaarta J, Matthews B, Cock IE. Kakadu plum fruit extracts inhibit growth of the bacterial triggers of rheumatoid arthritis: Identification of stilbene and tannin components. Journal of Functional Foods. 2015;17:610-20. DOI: 10.1016/j. jff.2015.06.019

12. Sirdaarta J, Matthews B, White A, et al. GC-MS and LC-MS analysis of Kakadu plum fruit extracts displaying inhibitory activity against microbial triggers of multiple sclerosis. Pharmacognosy Communications. 2015;5(2):100-15. DOI: 10.5530/pc.2015.2.2

13. Courtney R, Sirdaarta J, Matthews B, et al. Tannin components and inhibitory activity of Kakadu plum leaf extracts against microbial triggers of autoimmune inflammatory diseases. Pharmacognosy Journal. 2015;7(1):18-31. DOI: 10.5530/ pj.2015.7.2

14. Mbwambo ZH, Erasto $P$, Nondo RO. Antibacterial and cytotoxic activities of Terminalia stenostachya and Terminalia spinosa. Tanzania Journal of Health Research. 2011;13(2):1-8.

15. Cock IE, van Vuuren SF. Anti-Proteus activity of some South African medicinal plants: Their potential for the prevention of rheumatoid arthritis. Inflammopharmacology. 2014;22(1):23-36. DOI 10.1007/s10787-013-0179-3

16. Cock IE, van Vuuren SF. The potential of selected South African plants with antiKlebsiella activity for the treatment and prevention of ankylosing spondylitis. Inflammopharmacology. 2015;23(1):21-35. DOI: 10.1007/s10787-014-0222-z

17. Cock IE, van Vuuren SF. A comparison of the antimicrobial activity and toxicity of six Combretum and two Terminalia species from Southern Africa. Pharmacognosy Magazine. 2015;11(4):208-18. DOI 10.4103/0973-1296.149740

18. Cock IE, van Vuuren SF. South African food and medicinal plant extracts as potential antimicrobial agents. Journal of Food Science and Technology. 2015;52(11):6879-99. DOI: 10.1007/s13197-015-1806-3

19. Aneja KR, Sharma C, Joshi R. Antimicrobial activity of Terminalia arjuna Wight and Arn: An ethnomedicinal plant against pathogens causing ear infection. Brazilian Journal of Otorhinolaryngology. 2012;78(1):68-74

20. Shinde SL, Junne SB, Wadje SS, Baig MMV. The diversity of antibacterial compounds of Terminalia species (Combretaceae). Pakistan Journal of Biological Sciences. 2009;12(22):1483-6.

21. Chopra RN, Nayar SL, Chopra IC. Glossary of Indian medicinal plants New Delhi, CSIR, 1956.

22. Wright $\mathrm{MH}$, Courtney $\mathrm{R}$, Greene $\mathrm{AC}$, et al. Growth inhibitory activity of Indian Terminalia spp. against the zoonotic bacterium Bacillus anthracis. Pharmacognosy Communications. 2016;6(1):2-9. DOI: 10.5530/pc2016.1.2.

23. Kim HG, Cho JH, Jeong EY. Growth-inhibiting activity of active component isolated from Terminalia chebula fruits against intestinal bacteria. Journal of Food Protection®. 2006;69(9):2205-9. 
24. Arkhipov A, Sirdaarta J, Rayan P, et al. An examination of the antibacterial, antifungal, anti-Giardial and anticancer properties of Kigelia africana fruit extracts. Pharmacognosy Communications. 2014;4(3):62-76. DOI: 10.5530/pc.2014.3.7

25. Kalt FR, Cock IE. Gas chromatography-mass spectroscopy analysis of bioactive Petalostigma extracts: Toxicity, antibacterial and antiviral activities. Pharmacognosy Magazine. 2014;10(Suppl 1):S37-49. DOI: 10.4103/0973-1296.127338

26. Vesoul J, Cock IE. The potential of Bunya Nut as an antibacterial food agent Pharmacognosy Communications. 2012; 2 (1):72-9. DOI: 10.5530/pc.2012.1.13

27. Cock IE, Winnett V, Sirdaarta J, et al. The potential of selected Australian medicinal plants with anti-Proteus activity for the treatment and prevention of rheumatoid arthritis. Pharmacognosy Magazine. 2015;42(Supp 1):S190-S208. DOI: 10.4103/0973-1296.157734

28. Sautron C, Cock IE. Antimicrobial activity and toxicity of Syzygium australe and Syzygium luehmannii fruit extracts. Pharmacognosy Communications. 2014;4(1):53-60. DOI: 10.5530/pc.2014.1.8

29. Wright MH, Matthews B, Greene AC, et al. Growth inhibition of the zoonotic bacteria Bacillus anthracis by high antioxidant Australian plants: Newleads for the prevention and treatment of anthrax. Pharmacognosy Communications. 2015; 5(3):173-89. DOI: 10.5530/pc.2015.3.3

30. Boyer $\mathrm{H}$, Cock IE. Evaluation of the potential of Macadamia integriflora extracts as antibacterial food agents. Pharmacognosy Communications. 2013;3(3):53-62 DOI: $10.5530 /$ pc.2013.3.10

31. Cock IE. Assessment of the toxicity of selected Australian native plant extracts using the Artemia franciscana nauplii bioassay. Internet Journal of Toxicology. 2008; 5(2)
32. Ruebhart D, Wickramasinghe W, Cock IE. Protective efficacy of the antioxidants vitamin E and Trolox against Microcystis aeruginosa and microcystin-LR in Artemia franciscana nauplii. Journal of Toxicology and Environmental Health, Part A. 2009;72(24):1567-75. DOI: 10.1080/15287390903232459

33. Cock IE, Ruebhart DR. Comparison of the brine shrimp nauplii bioassay and the ToxScreen-II test for the detection of toxicity associated with Aloe vera (Aloe barbadensis Miller) leaf extract. Pharmacognosy Research. 2009; 1(2):98-101.

34. Buzzini P, Arapitsas P, Goretti M. Antimicrobial activity of hydrolysable tannins Mini-Reviews in Medicinal Chemistry. 2008;8:1179-87.

35. Wolinsky LE, Sote EO. Isolation of natural plaque-inhibiting substances from 'Nigerian chewing sticks'. Caries Research. 1984;18(3):216-25.

36. Hogg SD, Embery G. Blood-group-reactive glycoprotein from human saliva interacts with lipoteichoic acid on the surface of Streptococcus sanguis cells. Archives in Oral Biology. 1982;27(3):261-8.

37. Wu-Yuan CD, Chen CY, Wu RT. Gallotannins inhibit growth, water-soluble glucan synthesis, and aggregation of Streptococci mutans. Journal of Dental Research. 1988;67(1):51-5

38. Cock IE. The phytochemistry and chemotherapeutic potential of Tasmannia lanceolata (Tasmanian pepper): A review. Pharmacognosy Communications. 2013:3(4):1-13. DOI: 10.5530/pc.2013.4.3

39. Narayana KR, Reddy MS, Chaluvadi MR. Bioflavonoids classification, pharmacological, biochemical effects and therapeutic potential. Indian Journal of Phar macology. 2001;33(1):2-16.

\section{PICTORIAL ABSTRACT}

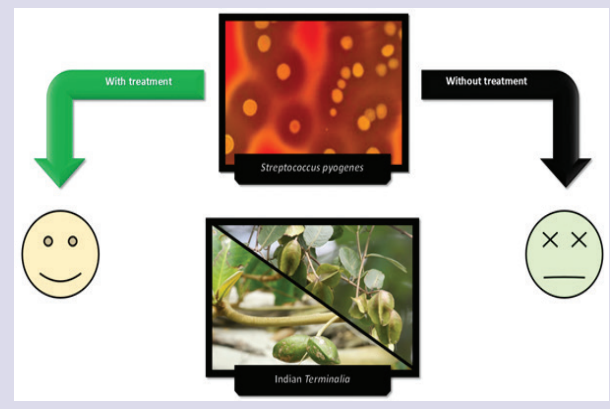

\section{SUMMARY}

- Methanolic and ethyl acetate T. arjuna, T. catappa and T. chebula extracts were potent inhibitors of $S$. pyogenes growth.

- $\quad$ The T. catappa and T. chebula ethyl acetate extracts were particularly potent with MIC values of 225 and $205 \mu \mathrm{g} / \mathrm{mL}$ respectively.

- The methanolic extracts of all Indian Terminalia spp. were also potent growth inhibitors with MIC values $268-425 \mu \mathrm{g} / \mathrm{mL}$.

- The T. catappa hexane extract was also a good S. pyogenes growth inhibitor (MIC $768 \mu \mathrm{g} / \mathrm{mL}$ )

- $\quad$ All other extracts were either ineffective S. pyogenes growth inhibitors or were of only low efficacy.

- All Indian Terminalia spp. extracts were nontoxic in the Artemia nauplii assay.

\section{ABOUT AUTHORS}

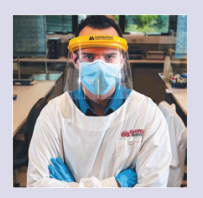

Dr. Mitchell Wright: Received his PhD in 2014, for his work investigating the manganese reduction and oxidation characteristics of environmental bacteria. He is currently a postdoctoral researcher at Griffith University, Australia, where he is working on several projects both in the areas of geomicrobiology and pharmacognosy. His present research interests are the use of bacteriogenic manganese oxides in the bioremediation of metal-contaminated sites as well as the use of Australian native plants in the treatment and prevention of various pathogenic bacteria.

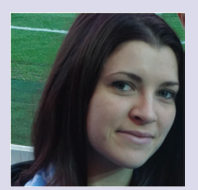

Ms. Megan Arnold: Is currently undertaking her PhD in Tropical Parasitology at Griffith University's Eskitis Institute for Drug Discovery with a focus on the identification and development of novel chemoprophylactic agents for malaria. Her other research interests include investigating Australian high antioxidant plants for their antibacterial capabilities.

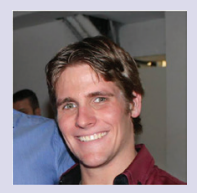

Mr. Cameron Lee: Completed his Bachelor of Science (BSc) in 2015 and is currently concluding his honours year. His research involves the investigation of thermophilic anaerobes that utilize toxic metals in anaerobic respiration (including uranium and arsenic). He has extensive experience in anaerobic cultivation/isolation and in numerous analytical techniques associated with heavy metal analysis.

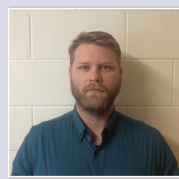

Mr. Reece Courtney: Is a current postgraduate student in the School of Natural Sciences Griffith University, Australia under the supervision of Dr lan Cock. His research interests include medical microbiology, pharmacognosy and medicinal plants. He has a particular interest in the medicinal properties of the genus Terminalia, which is the subject of his research project. 


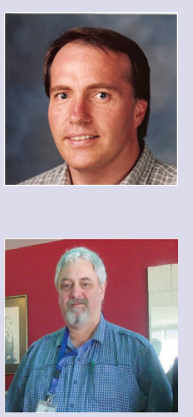

Dr. Anthony Greene: Is a senior lecturer and researcher at Griffith University, Brisbane Australia. He obtained his PhD in Microbiology from the University of New South Wales and focuses on extreme environments, Bioremediation and Geomicrobiology. His specific interests include the microbial ecology of thermophilic, saline and alkaliphilic environments and the mechanisms and industrial potential of extremophilic bacteria contained therein.

Dr. Ian Cock: Leads a research team in the Environmental Futures Research Institute and the School of Natural Sciences at Griffith University, Australia. His research involves bioactivity and phytochemical studies into a variety of plant species of both Australian and international origin, including Aloe vera, South Asian and South American tropical fruits, as well as Australia plants including Scaevola spinescens, Pittosporum phylliraeoides, Terminalia ferdinandiana (Kakadu plum), Australian Acacias, Syzygiums, Petalostigmas and Xanthorrhoea johnsonii (grass trees). This range of projects has resulted in nearly 200 publications in a variety of peer reviewed journals. 